\title{
Controle, flagrante e prazer: regimes escópicos e atencionais da vigilância nas cidades*
}

\section{RESUMO}

O artigo analisa regimes escópicos e atencionais presentes em dispositivos e práticas de vigilância nas cidades atuais. Pretende-se mostrar como tais regimes envolvem não apenas procedimentos de controle, mas, também, circuitos de prazer, atualizando as relações entre vigilância e espetáculo na cultura contemporânea. Nesta mistura de controle e prazer destaca-se uma lógica e uma estética do flagrante presentes no olhar e na atenção vigilantes sobre a cidade e os indivíduos que nela circulam. Três campos de análise serão privilegiados: a incorporação da vídeo-vigilância aos espaços públicos e semi-públicos, a produção e difusão de imagens amadoras e os sistemas informacionais e cartográficos de visualização do espaço urbano.

\section{PALAVRAS-CHAVE}

vigilância

prazer

controle

\section{ABSTRACT}

This paper examines the scopic and attentional regimes related to surveillance technologies and practices in contemporary cities. Such regimes involve not only control procedures, but also pleasure circuits, renovating the interplay between surveillance and spectacle in contemporary culture. Three fields of research will be prioritized: the incorporation of video surveillance into public and semi-public spaces, the production and distribution of amateur images and the cartographic information systems of visualization of urban space.

\section{KEY WORDS}

surveillance

pleasure

control
Cidades implicam arquiteturas de vigilância. As cidades modernas, em particular, crescem juntamente com a ampliação dos sistemas de vigilância sobre os indivíduos e as massas urbanas (Starobinsky, 1988; Lyon, 1994). Aqui já indicamos um primeiro postulado acerca das relações entre vigilância e cidade: os dispositivos de vigilância não são exteriores à dinâmica urbana, mas lhe são imanentes. Não são, pois, maquinações de forças externas de dominação, mas intrínsecos ao processo de modernização e suas práticas de gestão racional das instituições, da produção, do governo, da saúde, da segurança dos estados e das populações, etc. Nesse sentido, a vigilância urbana contemporânea é, em parte, herdeira do "desejo de eficiência, velocidade, controle e coordenação" (Wood et alii, 2006) da administração moderna. No entanto, uma série de transformações nos distancia dos modelos modernos de vigilância, tanto no âmbito dos dispositivos, quanto no âmbito da sua significação social e dos procedimentos de controle na sociedade contemporânea. Procuraremos, neste artigo, analisar alguns aspectos da vigilância urbana contemporânea, tendo em foco os regimes escópicos e atencionais presentes nas relações de vigilância na cidade. Os regimes escópi$\cos ^{1}$ compreendem, aqui, as ordenações do ver e do ser visto nas quais a vigilância é ou uma finalidade intencionada ou um efeito colateral e secundário. Os regimes atencionais ${ }^{2}$ concernem aos modos de orientar e exercer a atenção em contextos direta ou indiretamente voltados para a vigilância. A escolha por este foco de análise se deve a duas motivações. A primeira, mais estrutural, consiste no interesse de se explorar estes dois processos tão fortemente presentes nas relações de vigilância - as formas de ver/ser visto e de prestar atenção - num ambiente marcado pela dinâmica, dispersão e fragmentação como a cidade. Modos de ver são também modos de prestar atenção ${ }^{3}$, assim como vigiar envolve formas de focar e organizar o campo atencional tanto de quem vê quanto de quem é visto. Numa definição "funcional" da vigilância, Wood et alii (2006, p. 9) enfatiza o papel da atenção: "Where we find purposeful, routine, systematic and focused attention paid to personal details, for the sake of control, entitlement, management, influence or protection, we are looking at surveillance".

A segunda motivação é de teor histórico e reside nas inúmeras e aceleradas mudanças que vêm ocorrendo recentemente, tanto nos modelos e práticas de visão e de atenção (Crary, 1999) quanto nos dispositivos e práticas de vigilância (Marx, 2004; Bogard, 1996; Lianos, 2003), as quais se refletem nas formas como visão, atenção e vigilância e se relacionam nos cenários urbanos contemporâneos. $\mathrm{Na}$ análise dos regimes escópicos e atencio-

\author{
Fernanda Bruno \\ Professora do Programa de Pós-Graduação em Comunicação da UFRJ/RJ/BR \\ fgbruno@matrix.com.br
}


nais da vigilância nas cidades atuais, notaremos que eles envolvem não somente procedimentos de controle, mas também circuitos de prazer. Nessa mistura de controle e prazer, destacaremos uma lógica e uma estética do flagrante presentes tanto no olhar quanto na atenção vigilante sobre a cidade e os indivíduos que nela circulam.

Uma brevíssima e seguramente incompleta apresentação da paisagem atual da vigilância urbana nos servirá de preâmbulo à análise dos processos aqui em foco. A paisagem é extremamente múltipla e complexa não apenas por conta da miríade de dispositivos de vigilância espalhados pelas cidades, mas, também, pela multiplicidade de funções, propósitos e afetos que os atravessam. Comecemos pelos dispositivos: câmeras de vigilância em lugares públicos, semi-públicos e privados, webcams pessoais ou institucionais, sistemas de controle de trânsito (câmeras, pardais, radares), sistemas de geolocalização $\left(\mathrm{GPS}^{4}, \mathrm{GIS}^{5}, \mathrm{RFID}^{6}\right)$, fronteiras e portões eletrônicos (senhas e cartões de acesso, scanners para pessoas e bens/produtos), mecanismos de autenticação e controle de identidade (cartões de identidade e dispositivos de identificação biométrica), tecnologias de informação e comunicação (computadores, telefones celulares), redes de monitoramento e cruzamento de dados informacionais, sistemas informacionais de coleta, arquivo, análise e mineração de dados (bancos de dados, perfis computacionais), entre outros. Alguns destes dispositivos tendem a funcionar conjuntamente, refletindo, no campo da vigilância, uma tendência à "convergência tecnológica" presente em outros setores, como o das telecomunicações.

A combinação de sistemas de vídeo-vigilância, bancos de dados, identificação biométrica e tecnologias de monitoramento, por exemplo, é cada vez mais comum e os sistemas "inteligentes" interconectados tendem a ser utilizados para monitorar movimentos e comportamentos de milhões de pessoas no espaço e no tempo. Além disso, nota-se que nem todos estes dispositivos estão diretamente ou intencionalmente voltados para o exercício da vigilância; esta, em muitos casos, é um efeito ou característica secundária de um dispositivo cuja função primeira é outra - um telefone celular com câmera, por exemplo, tem uma função primeira de comunicação e registro visual, mas pode ser apropriado como uma câmera de vigilância em certas ocasiões, tal como aconteceu no caso do enforcamento de Sadam Hussein, no atentado a bomba no metrô de Londres, entre muitos outros casos. Já se nota, aqui, o segundo aspecto que atesta o caráter diversificado da vigilância urbana contemporânea - ela se exerce, direta ou indiretamente, misturada a diversos processos e práticas, com propósitos e funções variadas: nas práticas de consumo e nas estratégias de marketing e publicidade; nas medidas de segurança e de coordenação da circulação de pessoas, informações e bens; nas formas e meios de comunicação e sociabilidade; na prestação de serviços; etc. Nesse sentido, a vigilância não deve ser entendida como uma ativi- dade sombria, coercitiva e dominadora, orquestrada por um Big Brother (Orwell, 2003). Assim como a vigilância moderna era inseparável da maquinaria estatal, burocrática e disciplinar do capitalismo industrial, a vigilância contemporânea é inseparável da maquinaria informacional, reticular e modular do capitalismo pós-industrial. Não é, portanto, boa nem má por natureza, assim como seus efeitos não se medem por suas intenções, como veremos adiante.

O caráter multifacetado da vigilância se faz notar nos afetos que hoje mobiliza: se por um lado ela se justifica ou se exerce pelo medo e pela promessa de segurança, ela também mobiliza ou expressa todo um circuito de libidos, prazeres e desejos. Devemos lembrar que a vigilância não é apenas herdeira da cinzenta maquinaria industrial-disciplinar, da empoeirada burocracia estatal e das luzes esclarecidas do Iluminismo. A vigilância também herda as cores e os prazeres da cultura do espetáculo ${ }^{7}$ que floresce junto com as cidades modernas. Ao mesmo tempo em que a sociedade moderna fez dos indivíduos um foco de visibilidade dos procedimentos disciplinares, ela os incitou e os excitou enquanto espectadores de toda uma cultura visual nascente, intimamente atrelada à vida urbana. Jonathan Crary (1994), apropriando-se de Foucault e o voltando, em parte, contra si mesmo, procura mostrar como vigilância e espetáculo não se opõem ${ }^{8}$, mas fazem parte de um mesmo solo de modernização da subjetividade. Neste solo, os indivíduos são ao mesmo tempo transformados em objetos de observação de uma série de controles institucionais e estudos científicos e em observadores atentos do sistema de produção e consumo, bem como da cultura visual de massa nascente. Observadores estimulados e excitados pelo fluxo movente da vida e das paisagens modernas, pela aceleração dos ritmos e deslocamentos, pela complexificação da vida urbana, pelo advento de novos objetos e mercadorias, bem como pelas novas tecnologias de produção e reprodução da imagem (fotografia, cinema, estereoscópio, etc). Constitui-se, assim, um novo regime sensorial em que a visão e a atenção ocupam lugares privilegiados - uma escopolifia e um voyeurismo de massa começam a se fazer cada vez mais presentes na relação com o outro e com o mundo moderno. Um mundo que se faz ver cada vez mais como imagem e segundo diversas mediações.

Hoje as relações entre vigilância e espetáculo são ainda mais estreitas e os limites que os diferenciam são cada vez mais tênues, como atesta a proliferação de reality shows em que aparatos de vigilância e confinamento são montados a serviço do entretenimento. $\mathrm{Ou}$ como mostram os diversos vídeos e fotos amadores que circulam na internet ou na grande mídia, evidenciando como o olhar vigilante se banaliza e se naturaliza na cultura contemporânea, podendo assumir funções variadas. Claro que, neste movimento, tanto a vigilância quanto o espetáculo se encontram transformados. Este último não cabe mais em boa parte das acepções debor- 
dianas $^{9}$ (Debord, 1967) e seus derivados mais ou menos fiéis, uma vez que assistimos às mudanças significativas nos modos de produção, acesso e difusão de imagens e produtos culturais com o advento e os desdobramentos recentes das tecnologias digitais de comunicação e de informação (Lemos, 2007).

No campo das imagens de vigilância, assistimos hoje a sua livre circulação, rompendo os limites espaciais, institucionais, técnicos e estéticos que outrora as circunscreviam. Elas circulam nos mais diferentes domínios - segurança, consumo, entretenimento, arte, sociabilidade - e refletem a mistura e transformação recíproca tanto da vigilância quanto do espetáculo, a reordenação dos modos de ver e de ser visto, a reorientação dos focos e práticas da atenção, o cruzamento das pulsões voyeurísticas e exibicionistas com as modulações do controle. Este cenário multifacetado da vigilância contemporânea está presente, claro, no modo como ela se atualiza na vida urbana atual. Veremos como as características gerais desse cenário reaparecem no contexto mais específico dos regimes escópicos e atencionais aqui visados.

\section{Regimes escópicos e atencionais da vigilância na cidade}

Quando lidamos com os regimes escópicos e atencionais da vigilância urbana contemporânea, as câmeras de diversos tipos (vídeo-vigilância, webcams, celulares, máquinas fotográficas, câmeras de vídeo) ocupam a frente da cena. Recentemente, sistemas informacionais de visualização da cidade por composição de imagens de satélite ou outros registros fotográficos (como o Google Earth e o Google Street View) têm se tornado mais acessíveis e difundidos, tendendo a integrar os modos atuais de prestar atenção nas cidades. Trataremos também destes sistemas, ainda muito recentes, explorando brevemente, neles, os temas e questões destacadas neste artigo.

\section{Câmeras de vigilância: controle e flagrante}

No âmbito das câmeras, vemos conviver diferentes tipos de olhar, de estados atencionais e de significação da vigilância. As câmeras de vigilância, mais claramente identificadas como instrumentos de inspeção, representam um olhar que pela sua multiplicação em inúmeros locais públicos, semi-públicos e privados tende à onipresença, descortinando a cidade e os corpos passantes. Vale notar que existem diferentes tipos de câmeras de vídeo-vigilância: reais ou falsas; públicas ou privadas; visíveis ou escondidas; analógicas ou digitais; com sistema de gravação ou não; com monitoramento em tempo real ou diferido; isoladas ou conectadas em rede; voltadas para indivíduos ou para coletivos; com fins de prevenção ou de intervenção; com filtros e análise sistemática de imagens ou não ${ }^{10}$; integradas a bancos de dados ou não ${ }^{11}$. Além disso, tais câmeras podem operar segundo diferentes funcionalidades: controle do acesso; controle da conduta; testemunho e registro de atos ou "evidências"; controle de fluxos e deslocamentos de populações e bens, etc. Embora sempre represente uma instância de observação, a câmera de vigilância pode "agir" tanto segundo uma "eficácia simbólica", atuando como signo que dissuade a realização de comportamentos indesejáveis, quanto como olho que captura ou registra efetivamente a ação. As câmeras destinadas ao controle do acesso ao metrô, por exemplo, não são o instrumento efetivo de permissão ou negação do acesso (sendo este controlado efetivamente por bilhetes, portões eletrônicos e guardas) e por vezes não estão colocadas na entrada nem na saída das estações, mas em outras localidades. Funcionam, portanto, sobretudo como signo de uma retórica da vigilância que institui nos usuários uma consciência tácita de estarem sendo observados (Müller e Boos, 2004). Outras câmeras atuam como olho atento e vigilante capaz de intervir no momento mesmo da ação ou produzir registros para medidas posteriores. Um exemplo recente de controle em tempo real nos é dado pelas "câmeras falantes"12 destinadas a advertir indivíduos flagrados cometendo pequenas infrações, como jogar lixo na rua, atravessar a rua fora da faixa de pedestres, etc.

A despeito das diferenças de tipo e funcionalidade dos sistemas de vídeo-vigilância, pode-se extrair alguns aspectos gerais quanto às relações ver/ser visto e as modalidades de atenção neles implicadas, a sua significação social e às formas de exercer controle sobre indivíduos e populações. Três aspectos nos interessam destacar.

O primeiro se deve em boa parte ao próprio dispositivo que tem como característica ser uma instância de inspeção cujo sujeito da ação, ou melhor, do olhar, não está presente na cena, mas nem por isso é neutro. As câmeras de vigilância funcionam como uma espécie de terceiro olho opaco, impessoal e transinstitucional na dinâmica social, frente ao qual não há negociação possível, constituindo uma dessimetria espacial, temporal e social entre a instância de observação e os indivíduos observados. A opacidade e impessoalidade do olhar das câmeras não se devem apenas ao fato de não podermos ver quem está observando, mas também ao fato de esta imagem ser potencialmente objeto de múltiplos olhares de uma cadeia institucional qualquer. Um conjunto de câmeras com sistema de monitoramento e registro dispostas em um shopping center, por exemplo, pode ser inspecionado tanto pelos operadores encarregados, quanto pelo pessoal da segurança, policiais, funcionários do shopping, jornalistas, procuradores, pesquisadores, ou seja, qualquer um que tenha poder e interesse de observar a imagem registrada.

Trata-se, assim, de um observador proteiforme distante e disperso no arquipélago institucional. Eis porque, além de opaco e impessoal, o olhar da câmera é transinstitucional (Lianos, 2001, p.125).

Ademais, funciona como um terceiro olho que, embora seja em parte uma extensão da função normativa do olhar social, exclui qualquer intersubjetividade possível e, conseqüentemente, qualquer negociação e interação "olho a olho", sendo ao mesmo tempo emissor e receptor 


\section{da imagem.}

Há, pois, um desequilíbrio entre a instância de observação e os indivíduos observados, o qual se dá ao menos em três níveis. No nível espacial, pois a imagem da ação observada não se passa no mesmo lugar em que a ação se dá. No nível temporal, específico para a imagem registrada, pois não se trata apenas de ver, mas de rever e recriar o olhar quantas vezes se desejar, produzindo uma imagem indefinidamente estocada para o futuro, tornando o seu "destino", a sua significação bem mais incertos, suspensos e sujeitos a um olhar a posteriori. Por fim, o desequilíbrio social concerne à dissimetria na relação de poder entre o observador e o observado, na medida em que a impossibilidade de ver e negociar com o sujeito do olhar tornam o indivíduo sob a vigilância relativamente passivo e impotente frente a sua própria imagem, que é de algum modo confiscada pela câmera.

O segundo aspecto geral da significação social e da forma de controle exercida pela incorporação da vídeovigilância aos espaços públicos e semi-públicos consiste na produção de uma indiscernibilidade entre vítimas e suspeitos, bem como entre segurança e ameaça.

Diferentemente dos dispositivos de inspeção modernos, que vigiavam um conjunto predefinido de indivíduos cuja presença se devia à própria instituição que as vigiava - prisioneiros, enfermos etc - as câmeras de vigilância em ruas, metrôs, parques públicos, entre outros, são dirigidas a todos e a qualquer um, cumprindo, como vimos, uma função prioritariamente dissuasiva e preventiva. Os indivíduos aí não têm uma identidade individual nem coletiva que justifique a vigilância, sendo o acaso de transitarem num mesmo espaço inspecionado o único fato que os une. Somos todos igualmente vítimas e suspeitos potenciais, assim como a consciência da vigilância representa simultaneamente segurança e ameaça.

Por fim, o terceiro aspecto consiste nas consequiências normativas do tipo de observação e controle exercidos pelas câmeras de vigilância. O efeito normativo das câmeras deriva de um tipo de atenção voltado para a captura do excepcional, do irregular. Ou seja, as câmeras não se destinam tanto a introduzir uma normalidade no seio de uma população desviante (como no caso das instituições panópticas) quanto capturar ou flagrar uma fratura na ordem corrente. Tanto os humanos por trás das câmeras quanto os softwares de identificação de movimentos suspeitos podem executar essa tarefa de flagrar uma ruptura na normalidade, ou mesmo antecipá-la. Um exemplo recente engenhoso é o Hostil Intent, projeto para o desenvolvimento e implementação de um programa computacional de análise de imagens de câmeras de vigilância, monitoradas remotamente em tempo real. O programa pretende ser capaz de descobrir pistas acerca do estado mental e das intenções futuras de indivíduos através da análise de traços comportamentais e fisiológicos, como micro-expressões involuntárias do rosto, permitindo medidas preventivas. Por parte dos observados, as câmeras são incorporadas a uma arquitetura da regularidade e usualmente tendem a ser quase "esquecidas" na medida em que a sua presença e sua retórica dissuasiva são assimiladas e naturalizadas, mantendo-se na margem do foco de atenção da massa dos corpos vigiados, só ocupando a frente da cena quando está em jogo uma ruptura mais ou menos intensa da regularidade corrente. Vale contudo notar que a ordem e a regularidade são mantidas não tanto por uma interiorização de valores que orientam um projeto identitário ou biográfico, tal como previam as instâncias normalizadoras modernas.

As câmeras têm um efeito normativo "formal", "pragmático" e "utilitário", em que "parecer normal" é mais decisivo do que "ser normal". A normalidade é antes um efeito de superfície derivado da retórica dissuasiva das câmeras de vigilância. A adesão a modelos "práxicos" predominantes e o pertencimento a um "ethos" particular - o cliente de supermercado ou de banco, o passageiro de avião, o usuário de metrô etc - são mais importantes que a interiorização dos valores sociais de que tais modelos são uma das muitas expressões. É nesse sentido que podemos afirmar que o campo normativo atrelado às câmeras de vigilância é constituído por comportamentos que refletem uma norma sem valor.

\section{Câmeras e imagens amadoras: flagrante e prazer}

Juntamente com as câmeras de vigilância, as câmeras de telefones celulares, fotográficas e de vídeo, embora não estejam diretamente voltadas para o exercício da vigilância, participam ativamente da construção de um regime escópico sobre a cidade que se passa não tanto nos circuitos de controle, mas sim nos circuitos de prazer, entretenimento e voyeurismo, onde vigoram uma atenção vigilante e a captura do flagrante.

As câmeras fotográficas e de vídeo, cada vez mais portáteis e presentes no cotidiano dos indivíduos, especialmente a partir da difusão dos telefones celulares com câmeras, multiplicam os olhares sobre a cidade, fazendo dos corpos passantes olhos que não apenas vêem, mas registram e transmitem, à distância, cenas da cidade. Olhos eletrônicos locais com alcance e conexão global, olhares simultaneamente privados e públicos, individuais e coletivos. Recentemente, vemos crescer o número de episódios e de imagens capturadas por câmeras privadas em espaços públicos circulando tanto na Internet (weblogs, fotologs, Youtube) quanto na televisão e na imprensa. Casos célebres como o vídeo "erótico" da Daniela Cicarelli com seu namorado numa praia na Espanha, o enforcamento de Saddam Hussein, imagens do atentado a bomba no metrô de Londres e cenas do acidente com o avião da TAM em São Paulo circularam em diversos meios de comunicação, da grande mídia a Internet. Ao lado deles, inúmeras outras imagens de fotografia e vídeo capturadas por indivíduos nos espaços públicos das cidades circulam cotidiana e profusamente em sites decompartilhamento de vídeoe fotografias, weblo- 
gs, fotologs. Estas imagens constituem um repertório diversificado e relativamente desordenado dos inúmeros olhares sobre a cidade e seus sentidos e efeitos são múltiplos.

Há, contudo, em muitas delas, um traço comum que as tornam imagens de vigilância, no sentido contemporâneo que estamos dando a este termo - uma estética do flagrante resultante de um olhar amador que reúne aspectos simultaneamente policiais, libidinais e jornalísticos. Em alguns casos, tal estética do flagrante pende mais para o policial e/ou o jornalístico, buscando cenas de suposto interesse público em tom de denúncia e motivados por uma atitude "cidadã". Parte do chamado jornalismo "cidadão" e "participativo" nos dá inúmeros exemplos, tanto na Internet quanto na grande mídia, convocando amadores a enviarem as imagens disparadas por suas câmeras. A campanha Oi Cidadão, Flagrantes de Cidadania, do A Voz do Cidadão ${ }^{13}$, por exemplo, convida os internautas a flagrarem cenas de descaso público e político nas cidades. A chamada da campanha explicita os nexos entre o jornalístico e o policial, convocando o telefone celular como uma "câmera-arma":

Faça do seu celular uma arma a favor da plena cidadania! Fotografe situações de cidadania exemplar como estas que estão aqui embaixo e envie para nós com um relato sobre o flagra e a lição que você acha que pode tirar e passar adiante. Se aprovadas, você terá suas imagens divulgadas aqui nesta página e ainda receberá um certificado de Cidadão Exemplar da Voz do Cidadão (Disponível em: http:// www.avozdocidadao.com.br/detailConteudo. asp?ID $=5 \& M=5 \% 2336)$.

A grande mídia também convoca o "olhar cidadão" em colunas como o Eu repórter, de O Globo Online ${ }^{14}$, ou o Foto Repórter, do Estadão ${ }^{15}$. Sabe-se que a inovação não reside no uso do flagrante capturado por câmeras amadoras, já há muito tempo comum no jornalismo. A "novidade" consiste na intensificação desta prática e no "efeito de real" (Barthes, 2004) que tais imagens hoje produzem, como veremos adiante.

Há, ainda, projetos, de natureza distinta, que usam as múltiplas funções de registro, localização, comunicação e conexão dos telefones celulares ${ }^{16}$ para divulgar imagens que visam dar visibilidade e incitar uma sensibilidade política para contextos de miséria, guerra ou injustiças sociais que usualmente ficam de fora da agenda imagética midiática ${ }^{17}$. Outros projetos investem numa perspectiva mais pessoal sobre a cidade, convidando indivíduos ou grupos a narrarem o seu cotidiano em imagens usando celulares com câmera integrada e a Internet para registro e difusão. Desta forma, experiências e olhares particulares sobre a cidade são publicizados de modo a gerar conhecimento e concernimento coletivos. Um interessante exemplo é o projeto zexe.net $t^{18}$ que divulga, em tempo real na Internet, imagens registradas por câmeras celulares de coletivos urbanos como os motoboys ${ }^{19}$ em São Paulo ou cadeirantes ${ }^{20}$ em Barcelona. Estes últimos capturam com suas câmeras os diversos obstáculos à sua circulação na cidade, como "barreiras arquitetônicas" ou carros estacionados indevidamente. Já os motoboys registram, por exemplo, o cenário complexo do trânsito e da cidade de São Paulo, com seus acidentes e imprevistos diários, entre outras cenas do cotidiano. Nestes últimos casos, trata-se menos de uma estética do flagrante do que da produção coletiva de uma sensibilidade política que por vezes escapa à parte jornalismo participativo ou cidadão.

Num outro conjunto de imagens, a estética do flagrante é carregada de uma libido do instante cuja atenção recai sobre o inesperado, o extraordinário, o incomum no fluxo da vida regular, ordinária e comum. O gozo do instante não é apenas o do clique e da captura do agora, já familiar com a fotografia instantânea, mas também e talvez até principalmente, o da distribuição e divulgação imediatas, fazendo do instante capturado um instante partilhado, ubíquo, conectado. Aqui, os olhares são mobilizados por um tipo de atenção que visa flagrar cenas picantes da vida urbana, sacando suas câmeras ágeis em registrar e distribuir. O flagrante é carregado de um erotismo e um voyeurismo que se mesclam a uma atitude policial e/ou jornalística ${ }^{21}$.

O ciberespaço, em especial a Internet, é o território privilegiado de circulação dessas imagens que não se endereçam a um espectador coletivo nem trazem consigo nenhum interesse público maior. Estas imagens que visam flagrar pequenas idiossincrasias urbanas voltamse para o espectador individual ou privado e seu gosto particular pelo insólito da vida cotidiana - uma roupa íntima flagrada entre um movimento e outro de um corpo passante, uma ligeira transgressão comportamental em um lugar público, o pequeno vexame de um corpo que cai inesperadamente, etc. Imagens muito similares àquelas que os paparazzi, as câmeras escondidas, os reality-shows, as pegadinhas e as vídeo-cassetadas nos habituaram a ver. Eis porque estas imagens de vigilância são também imagens do espetáculo. Imagens que divertem, entretêm, dão prazer, convidam ao voyeurismo e promovem uma reversibilidade jocosa entre o anônimo e o célebre, o público e o privado, pois aplicam à vida corrente e às pessoas comuns $o$ mesmo procedimento escópico e atencional outrora reservado às celebridades da grande mídia ou ao interesse do grande público.

Ainda que estas práticas de vigilância sejam de, algum modo, "menores", na medida em que nem sempre são coordenadas por instituições ou atores sociais organizados, mas muitas vezes exercidas de modo relativamente disperso por inúmeros indivíduos, elas não são pouco significativas nem isoladas.

Elas compõem um cenário multifacetado, expressando e testemunhando a tendência à naturalização da vigilância como modo de olhar e prestar atenção na cultura contemporânea e, em particular, nas cidades. 
Muitos dos elementos presentes neste olhar e nesta atenção vigilantes, bem como o que estamos chamando aqui de estética do flagrante, não são novidades absolutas do nosso tempo. O registro fotográfico ou fílmico de flagrantes criminais, sexuais, jornalísticos e seu uso como prova irrefutável do "real" foram amplamente aplicados tanto nos processos policiais e judiciais, quanto na imprensa, no cinema documental ou ficcional e na literatura (Gunning, 2004). Sabe-se o quanto o testemunho fotográfico gozou, na modernidade, de um poder de evidência tal que fazia da imagem uma prova visual e irrefutável do ato criminoso, o que fez da fotografia um importante instrumento de vigilância e controle policial e criminal (Gunning, op. cit. Sekula, 1986). A suposição de que "o aparelho não pode mentir" (Gunning, op.cit.) dotava o culpado de uma visibilidade inextirpável e o flagrante conferia à imagem uma pontualidade que ampliava ainda mais o seu poder de prova. Também não é recente a presença dessas imagens e dessa estética da vigilância na indústria do entretenimento e na arte. Segundo Tom Gunning (op.cit.), a presença da câmera como testemunha dá-se, inclusive, antes no teatro, na literatura e no cinema modernos do que na justiça criminal. Os vínculos deste olhar e desta atenção vigilante com a sexualidade e o erotismo tampouco são novidades. O mesmo autor suspeita de que inicialmente a vigilância fotográfica tenha sido mais usada para flagrantes sexuais e suspeitas conjugais do que para crimes. A excitação do flagrante fotográfico rendeu a Freud uma interpretação muito particular de uma paciente que sofria de paranóia e que se convencera de estar sendo fotografada, tendo mesmo ouvido a batida ou o clique que supunha vir do obturador da câmera. Freud atribui à alucinação de sua paciente um deslocamento auditivo da vibração de seu clitóris excitado (Freud, 1980).

Além de ser um modo de exercer a atenção, o flagrante é, também na modernidade, um meio de atrair e capturar a atenção do espectador. Em sua análise da dimensão "neurológica" da modernidade, Ben Singer (2004) mostra como os sentidos modernos são submetidos a uma hiperestimulação na qual vigorava uma "estética do espanto". Seja na imprensa ou no entretenimento popular sensacionalista, as representações dos acidentes urbanos ressaltavam o que eles continham de mais grotesco e extremo, sendo comum a representação da vítima no instante do choque, acompanhada de uma testemunha surpresa e assustada.

Como se pode notar, muitos aspectos dos regimes escópicos e atencionais da vigilância nas cidades contemporâneas não são plenamente novos. Entretanto, reconhecer a sua anterioridade histórica não implica descartar qualquer especificidade atual. A estética do flagrante hoje ainda guarda a excitação pela surpresa e pelo espanto de outrora em diversos setores do entretenimento popular, mas no que diz respeito aos flagrantes da vida urbana atual, há um reposicionamento do observador que merece ser considerado. Este não apenas assiste ao espetáculo da dinâmica urbana e suas representações visuais como um ponto na massa, mas produz e distribui, com suas câmeras portáteis e conectadas, um microespetáculo do cotidiano, sendo ao mesmo tempo testemunha individual e difusor global da vida urbana.

O olho munido do clique instantaneamente disparado e conectado é ao mesmo tempo um ponto de observação e de difusão. Eis porque, dentre outros fatores já apontados, as imagens que daí derivam podem não ser apenas o registro de um olhar que casualmente testemunha algo, mas se tornarem ou terem o efeito de uma imagem de vigilância.

E o apelo destas imagens na captura da atenção de outros espectadores espalhados diante de diferentes telas (de computador, de celular, de televisão) parece residir não somente no seu conteúdo, mas principalmente naquilo que na sua forma indica as condições de sua produção, tornando-as ainda mais "eficazes" como imagens de vigilância. A precariedade e os ruídos das imagens amadoras indicam uma casualidade, uma urgência, um ar não intencional, não autoral, improvisado e não retocado que amplia o seu efeito de real e de vigilância. De algum modo, elas parecem não ter sido feitas por ninguém, ao mesmo tempo em que parecem ser de todos, circulando segundo modelos viróticos (Brasil, Migliorin, 2007) e incitando uma vigilância e um voyeurismo distribuídos. Neste âmbito, podemos dizer, como Koskela (2004), que os circuitos da vigilância não estão apenas representados nos sistemas relativamente "fechados" do "closed circuit television" das câmeras de vigilância, mas nas vias abertas do "open circuit television" das câmeras amadoras e telefones celulares.

\section{0 flagrante do zoom: voyeurismo liminar nos sistemas de visualização do espaço urbano}

Além das câmeras de diversos tipos, os recentes sistemas cartográficos e informacionais de visualização do espaço urbano a partir de imagens de satélite e de outros registros fotográficos disponibilizados na Internet e acessíveis a partir de dispositivos móveis, tendem a se tornar mais um dos dispositivos que compõem o olhar e a atenção vigilante sobre as cidades atuais. Refiro-me aos sistemas como o Google Earth ${ }^{22}$ e principalmente o Google Street View $w^{23}$ e outros similares a estes como o MapJack e EveryScape. Tais dispositivos ainda são muito recentes $\mathrm{e}$ tanto os seus usos sociais quanto os seus desdobramentos tecnológicos ainda estão indefinidos. No entanto, a repercussão que tais sistemas vêm alcançando, bem como as suas apropriações iniciais, já nos permite arriscar as primeiras impressões sobre a sua participação nas práticas de vigilância urbana. O Google Street View e similares (MapJack; EveryScape) vêm sendo cada vez mais usados como meios de visualização, orientação e também voyeurismo nos espaços urbanos. Os três programas são sistemas de visualização das cidades a partir de imagens no nível da rua com um panorama de 360 graus, vários níveis de zoom e boa resolução. As ima- 
gens são atreladas a mapas, permitindo ao usuário visualizar em detalhes, e com nitidez, trajetos, prédios, placas, pessoas transitando nas ruas, etc. Para além do uso funcional de localização e orientação nas cidades, tais sistemas vêm suscitando discussões sobre violação de privacidade, uma vez que algumas dessas imagens apresentam uma nitidez que permite identificar pessoas nas ruas, carros, janelas, etc ${ }^{24}$. Paralelamente, surgem também sites na Internet, como o Streetviewr.com, GeoTrotter.com, que brincam de coletar, receber e disponibilizar os "flagrantes" capturados inadvertidamente pelas câmeras destes serviços, em particular do Google Street View, o mais popular deles.

A "graça" da "brincadeira" é descobrir na imagem detalhes risíveis, curiosos, constrangedores ou picantes, casualmente. Simulando a perspectiva do pedestre e do passante, o Street View permite, pelo comando do zoom, um voyeurismo controlado sobre a imagem. Estes "flagrantes" são mais um exemplo de como a vigilância se torna uma prática cada vez mais banal na cultura contemporânea, exercida por qualquer um sobre qualquer outro, com propósitos diversos. Conjuga-se, mais uma vez, um olhar erótico e policial a uma postura jornalísti$\mathrm{ca}$ à procura de flagrantes. A mistura de voyeurismo $\mathrm{e}$ vigilância, de policial e libidinal se atualiza aqui num curioso regime de atenção e observação da cena urbana, em que o campo perceptivo é a própria imagem. Diferentemente das câmeras de celulares e de vídeo, nestes sistemas de visualização do espaço urbano a vigilância e o voyeurismo se dão em duas etapas ou segundo uma sobreposição de olhares. Primeiro, o olhar automatizado das câmeras que fotografa as ruas da cidade e, num segundo momento, os múltiplos olhares sobre a imagem em busca de detalhes que revelem algo escondido, produzindo uma espécie de strip-tease do espaço urbano. Trata-se aqui de um voyeurismo liminar, no sentido de que se situa entre o maquínico e o humano, entre o espaço físico e o informacional, entre a cidade e a imagem, entre os corpos e sua representação visual.

Além disso, a difusão destes dispositivos tende a construir um olhar cada vez mais mediado e híbrido sobre a cidade, adicionando não apenas camadas informacionais aos lugares públicos urbanos (Lemos, 2007), como também camadas escópicas e atencionais. Eles revelam, mais uma vez, um modo de olhar e prestar atenção na cidade que coloca em cena uma vigilância distribuída, que pode ser exercida por todos e sobre qualquer um.

As muitas faces da vigilância nas cidades contemporâneas certamente não se esgotam aqui. Vimos uma pequena parte das suas expressões atuais e segundo uma perspectiva particular, ressaltando os regimes escópicos e atencionais em curso. Identificamos de modo recorrente as íntimas relações entre vigilância e espetáculo, bem como uma naturalização do olhar e da atenção vigilantes tanto nos circuitos de controle (especialmente das câmeras de vigilância) quanto nos circuitos de prazer e voyeurismo presentes na produção, consumo e circulação de imagens amadoras e em alguns dos sistemas cartográficos e informacionais de visualização do espaço urbano. Propomos ainda a vigência de uma lógica e uma estética do flagrante nas relações de vigilância na cidade, em que se mesclam o policial, o libidinal e o jornalístico. Os diversos dispositivos e processos aqui analisados indicam o quanto a vigilância, em vez de ser um regime de visão e de atenção circunscrito a momentos e espaços de controle específicos, é incorporada ao repertório cultural, social, tecnológico, subjetivo e estético contemporâneo. Esta incorporação não implica a sua presença por toda parte, nem uma homogeneidade em sua forma; vimos como ela é múltipla e como seus sentidos e efeitos são diversos. Estes últimos, como já afirmamos, não se medem por suas intenções, o que aliás é próprio aos dispositivos, aos poderes e à estética em geral. O efeito-vigilância que testemunhamos resta aberto às apropriações e desvios imprevistos mFAMEcos

\section{NOTAS}

* Este artigo é resultado da pesquisa Visibilidade, vigilância e subjetividade nas novas tecnologias de informação e de comunicação, apoiada pelo CNPq (Bolsa de Produtividade em Pesquisa 2007-2010). Uma versão reduzida deste texto foi publicada no sítio eletrônico Estéticas da Biopolítca: audiovisual, política e novas tecnologias - Programa Cultura e Pensamento/ MINC e Revista Cinética

1 O termo regime escópico foi proposto por Christian Metz (1984) e retomado por Martin Jay (1993). O uso do termo neste artigo não espelha as concepções dos autores referidos, mas guarda delas a idéia, desenvolvida sobretudo por Jay, de que o regime escópico de uma dada época não consiste num campo visual unificado de teorias e práticas, mas sim num terreno de disputas em que concorrem modelos dominantes e uma série de sub-culturas visuais. Eis porque usamos aqui o termo no plural para designar os dispositivos e práticas do ver e do ser visto na cultura Contemporânea.

2 Nossa análise dos regimes atencionais inspira-se no trabalho de Jonathan Cray (1999) sobre a atenção na modernidade. Apropriamos-nos especialmente de parte da "metodologia" do autor, focalizando os dispositivos e práticas de governo da atenção nas suas relações com os processos sócio-culturais e de subjetivação em cada período histórico.

3 Embora esta não esteja restrita à visão, podendo envolver processos auditivos, olfativos, mnemônicos, estados de consciência, etc., Privilegiaremos os processos de atenção articulados à visão.

4 Sistema de posicionamento global por satélite. 
5 Sistema de informação geográfica: sistema informatizado para captura, armazenamento, verificação, integração, manipulação, análise e visualização de dados relacionados a posições na superfície terrestre.

6 Identificação por radiofreqüência: sistema de identificação automática através de sinais de rádio, capaz de recuperar e armazenar dados remotamente por meio de etiquetas RFID. Tais etiquetas são chips atrelados a antenas que podem ser colocados em Produtos, animais ou pessoas, permitindo que estas sejam rastreadas e identificadas remotamente.

7 O termo cultura do espetáculo refere-se, aqui, à emergência de uma cultura visual de massa, no século XIX, constituída tanto pelos dispositivos de entretenimento visual e de produção de imagem de então (esterescópio, fotografia, cinema etc), quanto pelas novas estimulações sensoriais propiciadas pelo crescimento das cidades, pela aceleração dos deslocamentos e pelos modelos de consumo nascentes. Neste cenário, conforme Crary (1999) dá-se uma reorganização dos modelos de percepção e de atenção, fundando um novo tipo de observador. Essa cultura visual de massa prepara e serve de pré-história à sociedade do espetáculo, no sentido que Guy Debord dá ao termo, cujo início, ainda segundo Crary (1999), se daria no fim dos anos de 1920 e coincidiria com as origens da televisão, o ínício da sonorização no cinema, a utilização das técnicas dos mass media pelo partido nazista na Alemanha, o triunfo do urbanismo e o fracasso político do surrealismo na França.

8 O autor cita a célebre frase de Foucault - «Notre société n'est pas celle du spectacle, mais de la surveillance [...]. Nous ne sommes ni sur les gradins ni sur la scène, mais dans la machine panoptique » (apud Crary, 1994, op. cit., p. 42) - para argumentar que a oposição proposta por Foucault parece ignorar que estes dois regimes de poder podem coincidir em seus efeitos.

9 Sobre as continuidades e rupturas entre o espetáculo contemporâneo e aquele proposto e analisado por Debord, ver Bruno e Pedro (2004) e Freire Filho (2003).

10 Há câmeras de vigilância cujas imagens são Automaticamente analisadas por programas computacionais segundo filtros específicos (movimento, forma, entre outros).

11 Certamente, essa tipologia não esgota as Modalidades de câmeras de vigilância nos espaços públicos e semi-públicos, mas oferece um panorama dos seus principais tipos hoje utilizados. Além disso, há várias tipologias possíveis, variáveis conforme os princí- pios de classificação empregados: atributos técnicos, função, efeito, entre outros. Para uma tipologia de câmeras de CCTV em espaço público, Cf. Müller, C. \& Boos, D. (2004).

12 Estas câmeras são acompanhadas de um alto-falante que adverte os indivíduos no ato da infração. Inicialmente utilizadas no Reino Unido, o Brasil já conta com alguns exemplares das câmeras falantes nas cidades de Piracicaba (SP) e São Sebastião (SP).

13 www.avozdocidadao.com.br/

14 http://oglobo.globo.com/participe/default.asp

15 http://www.estadao.com.br/ext/fotoreporter/ foto_imagens.htm

16 O holandês Skoeps (www.skoeps.com/), por exemplo, é um sítio de notícias plenamente constituído de imagens feitas por câmeras amadoras de telefones celulares.

17 Ver, por exemplo, o África News - http:// www.africanews.com/site/page/photography

18 http://www.zexe.net

19 http://www.zexe.net/SAOPAULO/intro.php?qt=

20 http:// www.zexe.net/BARCELONA/ barcelona.php?can_actual $=74 \& q \mathrm{t}=7.1$

21 O vínculo entre esses termos também são visíveis nos sites e imagens pornográficas na Internet, amadores ou não. Seus nomes são em si reveladores: Cidade Amadora, Blitz erótica, Planeta Amadoras, Flagras\&amadoras, 00 Sexte, entre outros.

Devo a Ilana Feldman o insight sobre as relações entre o libidinal e o policial nas imagens amadoras. Tal relação é abordada pela autora em sua dissertação de mestrado (2007), embora num contexto distinto, o do reality show Big Brother Brasil.

22 http://earth.google.com

23 http://maps.google.com/help/maps/streetview

24 Após uma série de protestos em defesa da privacidade, a Google "apaga" os rostos de pessoas nas imagens disponibilizadas no Street View, mediante solicitação das mesmas.

\section{REFERÊNCIAS}

BARTHES, R. O rumor da língua. São Paulo: Martins Fontes, 2004. 
BOGARD, W. The Simulation of Surveillance: Hypercontrol in Telematic Societies. New York, NY: Cambridge University Press, 1996.

BRASIL, A., MIGLIORIN, C. Saddam e Cicarelli: nossas imagens. In: Revista Cinética. Disponível em: http:/ / www.revistacinetica.com.br/saddamcicarelli.htm.

BRUNO, F., PEDRO, R. M. L. R. Entre Aparecer e Ser: tecnolo-gia, espetáculo e subjetividade contemporânea. Intexto, Porto Alegre, v. 11, p. 1-10, 2004. Disponível em: http://www.intexto.ufrgs.br/n11/a-n11a9.html

CRARY, J. L'art de l'observateur: Vision et modernité au XIX siècle. Nîmes: Éditions Jacqueline Chambon, 1994

- Suspensions of Perception: Attention, Spectacle, and Modern Culture. Cambridge, MA, London: MIT Press, 1999.

FREIRE FILHO, J. A Sociedade do Espetáculo Revisitada. Famecos, vol. 22, p. 33-45,2003.

FREUD, S. Um caso de paranóia que contraria a teoria psicanalítica da doença. In ESB XIV. Rio de Janeiro: Imago, 1980.

GUNNING, T. "O retrato do corpo humano: a fotografia, os detetives e os primórdios do cinema". In: Leo Charney; Vanessa R. Schwartz. O cinema e a invenção da vida moderna. São Paulo: Cosac \& Naify, 2004.

JAY, M. Les régimes scopiques de la modernité. In: Réseaux. Septembre-octobre.

$1993, n^{\circ} 61$

KOSKELA, H. “Webcams, TV Shows and Mobile phones: Empowering Exhibitionism". In: Norris, C., McCahill, M. e Wood, D. (eds.). Surveillance \& Society CCTV Special. Vol. 2(2/3), 2004. Disponível em: http:/ /www.surveillance-and-society.org/cctv.htm.

LEMOS, A. "Comunicação e práticas sociais no espaço urbano: as características dos Dispositivos Híbridos Móveis de Conexão" Multirredes (DHMCM). In: Comunicação, mídia e consumo. São Paulo, v.4, n.10, p.2340, jul 2007.

LYON, D. The Electronic Eye: The Rise of the Surveillance Society. Minneapolis: University of Minnesota Press, 1994

LIANOS, M. Le nouveau controle social. Paris: L'Harmattan, 2001

. Le Contrôle Social après Foucault. Surveillance \& Society, v.1, n.3, p.431-438, 2003. Disponível em: http:/ / www.surveillance-and-society.org

MARX, G. 2004. What's new about the "new surveillance"? Surveillance and Society 1(1): 9-29. Disponível em: <http://www.surveillance-and-society.org>

MARZOCHI, I. F. Paradoxos do visível: reality shows, estética e biopolítica. Dissertação de mestrado, PPGCOM/ UFF, 2007.

METZ, C. Le Significant Imaginaire: Psychanalyse et Cinema. Paris: Bourgeois, 1984.

MÜLLER, C., BOOS, D. Zürich main railway station: $A$ typology of public CCTV systems. Surveillance and Society, 2(2-3), 2004. Disponível em: <http:// www.surveillance-and-society.org>

ORWELL, G. 1984. Rio de Janeiro: Nacional, 2003.

SEKULA, A. The Body and the Archive. In: October 39: 364, 1986.

SINGER, B. “Modernidade, hiperestímulo e o início do sensacionalismo popular". In: Leo Charney; Vanessa R. Schwartz. O cinema e a invenção da vida moderna. São Paulo: Cosac \& Naify, 2004.

STAROBINSKY, J. Os emblemas da razão. São Paulo: Companhia das Letras, 1989

WOOD, D. M. (Ed.). A Report on the Surveillance Society - For the Information Commissioner by the Surveillance Studies Network. Setembro, 2006 